\title{
The Brazilian Society of Rheumatology recommendations on investigation and diagnosis of systemic autoimmune myopathies
}

Fernando Henrique Carlos de Souza', Daniel Brito de Araújo², Verônica Silva Vilela³, Ricardo Santos Simões', Wanderley Marques Bernardo ${ }^{1}$, Thais Amanda Frank ${ }^{4}$, Bernardo Matos da Cunha ${ }^{5}$ and Samuel Katsuyuki Shinjo ${ }^{6^{*}}$

\begin{abstract}
Background: This research is recommended by the Myopathy Committee of the Brazilian Society of Rheumatology for the investigation and diagnosis of systemic autoimmune myopathies.

Body: A systematic literature review was performed in the Embase, Medline (PubMed) and Cochrane databases, including studies published until October 2018. PRISMA was used for the review, and the articles were evaluated, based on the Oxford levels of evidence. Ten recommendations were developed addressing different aspects of systemic autoimmune myopathy investigation and diagnosis.

Conclusions: The European League Against Rheumatism/ American College of Rheumatology (EULAR/ACR) classification stands out for the diagnosis of systemic autoimmune myopathies. Muscular biopsy is essential, aided by muscular magnetic resonance images and electroneuromyography in complementary research. Analysis of the factors related to prognosis with the evaluation of extramuscular manifestations, and comorbidities and intense investigation regarding differential diagnoses are mandatory.
\end{abstract}

Keywords: Autoantibodies, Electroneuromyography, Magnetic resonance, Muscle biopsy, Systemic autoimmune myopathies

\section{Background}

Systemic autoimmune myopathies (SAM) are rare systemic muscle diseases that include dermatomyositis (DM), juvenile dermatomyositis, clinically amyopathic dermatomyositis, polymyositis (PM), juvenile myositis, antisynthetase syndrome, inclusion body myositis, immune-mediated necrotizing myopathies, overlapped myositis syndrome, cancerassociated myopathies, and among others [1, 2].

Among the several diagnostic criteria proposed, convergence was observed in the evaluation of the following aspects: muscle weakness, observation of inflammatory infiltrate in muscle biopsy, electroneuromyography evaluation, serum muscle enzymes with special emphasis

\footnotetext{
* Correspondence: samuel.shinjo@gmail.com

${ }^{6}$ Disciplina de Reumatologia, Faculdade de Medicina FMUSP, Universidade de Sao Paulo, Av. Dr. Arnaldo, 455, $3^{\circ}$ andar, sala 3150, Sao Paulo, Cerqueira César CEP: 01246-903, Brazil

Full list of author information is available at the end of the article
}

on creatine phosphokinase (CPK), and specific myositis antibodies. Comorbidities should be investigated, highlighting the presence of neoplasia, and a thorough investigation must always be carried out with regard to differential diagnoses $[3,4]$.

The purpose of these recommendations is to guide the investigation and diagnosis of SAM patients according to the current evidence in the literature.

\section{Methods}

A systematic literature review was performed in the following databases: Embase, Medline (PubMed), and Cochrane. The analysis was performed according to each "PICO" question (Patient, Intervention, Control, Outcome).

The following English terms were used in the systematic review of the literature: Autoimmune OR Autoimmune Disease OR Autoimmune Diseases OR Systemic OR 
Polymyositis OR Idiopathic Polymyositis OR Idiopathic OR Dermatomyositis OR Dermatopolymyositis OR Dermatopolymyositis OR Myositis OR Inflammatory Muscle Diseases OR Inflammatory Myopathy OR Inflammatory Myopathies) AND (Muscular Disease OR Myopathies OR Muscle Disorders OR Muscle Disorders OR Myopathic Conditions OR Myopathic Conditions.

With the application of a random filter, the terms related to each modality of investigation and diagnoses for SAM were included.

The inclusion criteria for the present study were: randomized and controlled trials (RCT) addressing SAM diagnosis and investigation, extension studies derived from RCTs with the criteria mentioned above and systematic reviews with RCT meta-analysis. In some cases, review articles and historical cohort studies were included and, in the absence of RCTs for specific modalities of therapy, open studies or lowquality cohort studies were accepted.

The steps in this systematic review followed the PRISMA guidelines [5]. The selected studies were evaluated, and the quality of the evidence and level of agreement for each question was based on the level of evidence from the studies (Tables 1 and 2) [6-8]. Ten recommendations were developed addressing different aspects of SAM investigation and diagnosis.

\section{Recommendations}

\section{What are the classification criteria for SAM?}

From 3297 records identified through database searching, 10 studies were selected to answer the present question (Additional file 1).

\section{Literature review and analysis}

A series of diagnostic criteria for SAM was developed by Bohan and Peter, Dalakas, Tanimoto, Targoff and the European Neuromuscular Center (ENMC). The classification of Dalakas, with a sensitivity of $77.1 \%$ and a specificity of $99.0 \%$, showed better performance, followed by the ENMC criterion, with a sensitivity of $71.4 \%$ and a specificity of $82.4 \%$ (B) [9-14].
Table 2 Quality of evidence

\begin{tabular}{ll}
\hline Quality of evidence & Definition \\
\hline A & Consistent level 1 studies \\
B & Consistent level 2 or 3 \\
& studies or extrapolations \\
& from level 1 studies \\
& Level 4 studies or \\
C & extrapolations of level 2 \\
& or 3 studies \\
& Level 5 evidence or \\
D & with inconsistency \\
& or inconclusiveness \\
\hline
\end{tabular}

Medical records of adults diagnosed with DM according to the classification of Bohan and Peter were submitted to the European League Against Rheumatism / American College of Rheumatology (EULAR / ACR) criteria due to the inclusion of cutaneous rash (heliotrope rash and Gottron's sign or papules) [15]. DM cutaneous findings were measured by activity using the Severity Index and cutaneous dermatomyositis disease area (CDASI) to show which variables presented more frequently in patients with active DM including classic, amyopathic and hypomyopathic forms (C) [15].

The evaluation of the performance of EULAR / ACR in patients for whom a muscle biopsy was performed resulted in a sensitivity of $93 \%$ and specificity of $88 \%$; disregarding the histological criterion indicated a sensitivity of $87 \%$ and a specificity of $82 \%$ (B) $[2,16]$. Of note, the EULAR / ACR classification criteria [2] excluded the necessity of the electroneuromyography exam and aldolase serum dosing.

Similarly, all analyzed criteria showed the relevance of muscle biopsy, whose main objective is to rule out other possible causes of myopathies, in addition to helping to characterize the type of SAM. Biopsy is an important complementary exam in suspected cases of myopathies, especially in patients without characteristic skin involvement.

Overall, among the criteria, those of EULAR / ACR and ENMC performed better in the comparisons evaluated.

Table 1 Categories of evidence in studies

\begin{tabular}{ll}
\hline Levels & Evidence \\
\hline $1 \mathrm{a}$ & Systematic review and RCT meta-analysis \\
$\mathrm{ib}$ & At least one RCT with narrow confidence interval \\
$2 \mathrm{a}$ & Systematic review and meta-analysis of cohort studies \\
$2 \mathrm{~b}$ & At least one cohort study or low quality RCT \\
$3 \mathrm{a}$ & Systematic review and meta-analysis of case-control studies \\
$3 \mathrm{~b}$ & At least one case control study \\
4 & At least one case series or cohort study and low quality case-control studies \\
5 & Expert opinion without critical evaluation explicit or based on physiology, bench research or "fundamental principles" \\
\hline$R C T$ randomized clinical trial &
\end{tabular}




\section{Recommendations}

SAM classification criteria may help with diagnoses, provided other myopathies have been ruled out. Specifically, the EULAR / ACR criteria deserve special mention, mainly when associated with muscle biopsy (quality of evidence B; level of agreement >90\%).

\section{When should muscle biopsy be indicated in patients with SAM?}

From 9275 records identified through database searching, 14 studies were selected to answer the present question (Additional file 1).

\section{Literature review and analysis}

In defined DM, perifascicular, perimysial or perivascular infiltrate and perifascicular atrophy are present (D) [17]. In immune-mediated necrotizing myopathy, the biopsy predominantly shows necrotic muscle fibers, sparse inflammatory cells in the perivascular space, and infiltrate of the perimysium (D) [12].

In PM, muscle biopsy shows cytotoxic CD8+ $\mathrm{T}$ lymphocyte endomysial inflammatory infiltrate, in necrotic and nonnecrotic fibers expressing major histocompatibility complex (MHC)-I [18-22].

Due to the presence of inflammatory infiltrate and mononuclear cells in muscle biopsy, the diagnostic utility of MHC-I has been studied to differentiate in SAMs from other muscular diseases and may show interference by variations, for example, in antibody type and staining (B) $[18-22]$.

When comparing the histology of PM and DM with muscle biopsies of patients with muscular dystrophy, it was observed that MHC-I was regulated along the membrane of muscle fibers in patients with SAM, which helps in the differentiation from neuromuscular diseases (B) [18, 23, 24].

Therefore, when possible, rheumatologists should obtain muscle biopsy samples from all patients unless they present with unequivocal DM skin lesions (B) [24]. Moreover, immunohistochemistry (i.e., MHC staining) should $b$ also be included in routine muscle biopsy panel analysis whenever possible.

As mentioned in the previous recommendation, all criteria include muscle biopsy to better characterize SAM and to exclude myopathies from another origin.

\section{Recommendations}

Muscle biopsy in patients with SAM may aid in the diagnosis of their subtypes and differentiate this disease from noninflammatory myopathies. MHC labeling mainly contributes to differentiating SAM from muscular dystrophies (quality of evidence B, level of agreement >90\%).
When should magnetic resonance imaging of muscles be indicated in patients with SAM?

From 428 records identified through database searching, 5 studies were selected to answer the present question (Additional file 1).

\section{Literature review and analysis}

Analysis of the distribution and extension of muscle inflammation through full-body magnetic resonance imaging (MRI) in SAM patients and subsequent biopsy of the muscle guided by these findings are described as a potential aid in the diagnosis of these diseases (B) [25-27].

This technique allows for the early identification of oligosymptomatic myositis, accurately detecting the most severely affected muscle candidates for biopsy, providing a reliable baseline method to monitor disease progression and response to treatment (B) [25-27].

Although imaging diagnostic methods with MRI have not been included in the EULAR / ACR classification criteria [2], the ability to demonstrate possible patterns of tissue alteration shows the possibility of their use as a complementary method in differentiating acquired and hereditary myopathies.

\section{Recommendations}

Magnetic resonance images can be used as a guide to muscle biopsy, to identify oligosymptomatic myositis and possible kinds of myopathies, and to monitor disease progression and response to treatment (quality of evidence B, level of agreement > 90\%).

\section{When should electroneuromyography be indicated in patients with SAM?}

From 2064 records identified through database searching, 14 studies were selected to answer the present question (Additional file 1).

\section{Literature review and analysis}

Studies have demonstrated variable accuracy of electroneuromyography in different SAM, at similar rates in DM compared to PM (B) [28], and the evaluation of muscle fiber conduction velocity did not help to discriminate SAM from other myopathies (B) $[29,30]$.

In European centers, patients with myopathies of different etiologies, and even those with unknown etiologies were evaluated using three different diagnostic consensuses: clinical, electrodiagnostic and final consensus (clinical evaluations and electroneuromyography results). High sensitivity (90.2\%) of electroneuromyography was observed in SAM [31-33]. Nevertheless, due to its low specificity, electroneuromyography has been withdrawn from the new EULAR / ACR 2017 [2].

Complementary tests before and after 6 months and 12 months of treatment indicated that increased muscle 
strength and decreased serum enzyme levels were associated with decreased spontaneous activity and the proportion of high-frequency components in electroneuromyography, except during the initial treatment period, when a temporary increase of high-frequency components was recorded (C) [34].

It was also shown that fiber density was slightly higher in the normal or neurogenic subgroup than in the myogenic subgroup, but without statistical significance (C) [35]. Finally, motor unit potentials and a myopathic interference pattern were present in equal numbers in treated and nontreated DM patients (B) [36]. Therefore, electroneuromyography may have an additional role in the diagnosis of SAM but plays no role in its follow-up (B) [36]. The exam is also important to distinguish eventual muscular weakness secondary to neurogenic affection.

\section{Recommendations}

Electroneuromyography in the diagnostic investigation can identify patients with myopathies, but it plays no role in the follow-up (quality of evidence B; level of agreement $>90 \%$ ).

\section{What are the myositis-specific or myositis-related antibodies that can assist in the diagnosis and/or follow- up of SAM patients in daily practice?}

From 2974 records identified through database searching, 36 studies were selected to answer the present question (Additional file 1).

\section{Literature review and analysis}

Among the several antibodies identified, we present some antibodies that stand out in SAM.

Eight anti-aminoacyl-tRNA synthetase autoantibodies are described (A) [37]. The most prevalent is anti-Jo-1 (histidyl-tRNA synthetase), which can be identified in more than $20 \%$ of adult patients with a diagnosis of SAM (B) $[38,39]$ (C) [40], and due to its importance, this was included in the new EULAR / ACR 2017 SAM classification criteria [2]. Anti-Jo-1 is usually associated with manifestations that constitute the antisynthetase syndrome characterized by interstitial lung disease (ILD), Raynaud's phenomenon, arthritis and hyperkeratosis of the lateral part of the fingers and palms, a condition known as "mechanic hands." This antibody can also be found in cases of typical antisynthetase syndrome skin rashes. Other antisynthetase autoantibodies such as anti-PL-17 (threonyl-tRNA), anti-PL-12 (alanyltRNA), anti-EJ (glycyl-tRNA), anti-Ha (tyrosyl-tRNA), antiOJ (isoleucyl-tRNA), anti-Zo (phenylalanyl-tRNA) and anti-KS (asparagil-tRNA) are less commonly found in this clinical condition [37-40].

In addition, evidence suggests that some aspects of the disease could vary depending on which antibody is present. Muscle disease, for example, is most frequently present among patients positive for anti-Jo-1, anti-PL-7, and anti-EJ (B) [41]. Arthritis is most associated with anti-Jo-1 and antiPL-7; on the other hand, positivity of anti-KS, anti-OJ and anti-PL-12 is more associated with ILD (B) [37-42]. In addition, other myositis-specific and myositis-associated autoantibodies may be present, such as anti-melanoma differentiation-associated protein 5 (anti-MDA-5) and anti$\mathrm{PM} / \mathrm{Scl}$, respectively (B) [43]. The presence of anti-MDA-5 is associated with rapidly progressive ILD (A) [44]. It has been used as a marker of response to treatment $(B)[43,45]$ (C) [46] and of poor prognosis; more than $40 \%$ of antiMDA-5 positive patients die of respiratory failure (B) [47]. On the other hand, patients with anti-Jo-1 autoantibodies have better survival rates (B) [48].

Immune-mediated necrotizing myopathy is an SAM subtype associated with rapid development of muscle weakness and the presence of anti-signal recognition particle (antiSRP), a specific myositis autoantibody that occurs in the context of acute onset of the disease, with severe myopathy and aggressive disease $(C)[49,50]$. Dysphagia and ILD are also found in anti-SRP-positive patients (B) [51]. Anti-3hydroxy-3-methylglutaryl-coenzyme A reductase (antiHMGCR) is also associated with this myositis subtype, especially in patients with a previous history of statin use (B) [52] (D) [53]. An observational study designed to evaluate the severity of the disease and response to therapy in patients with myositis associated with the anti-HMGCR autoantibody found that young individuals had a more severe disease and a worse prognosis compared to older individuals (B) [54].

Anti-Mi-2 (directed against the nucleosome deacetylase complex) is associated with the phenotype of cutaneous signs ("shawl" sign, heliotrope rash and photosensitivity), clinically significant weakness, and high levels of muscle enzymes. The prognosis of patients with anti-Mi-2 is a good response to glucocorticoid treatment and a decreased risk of neoplasia and pulmonary disease (B) [55].

Myositis-specific autoantibodies related to a higher risk of malignancy in SAM patients include anti-transcriptional intermediary factors (TIF) $-\gamma$ and anti-nuclear matrix protein (NXP)-2 (B) [56-58].

Anti-Ku, anti-PM/Scl and anti-nuclear ribonucleoprotein (anti-RNP) antibodies are generally identified in patients with overlapping manifestations of myositis and other autoimmune systemic diseases such as scleroderma, systemic lupus erythematosus and mixed connective tissue disease [59]. These individuals are probably the largest subgroup of patients who are diagnosed with SAM, with a prevalence of up to $50 \%$ of all adult individuals (D) [59]. Although these manifestations are nonspecific, they may correlate with some clinical characteristics of SAM (B) $[60,61]$.

Anti-PM / Scl is most commonly found in the association of systemic sclerosis, conferring an increased risk of interstitial lung disease, arthritis, mechanic's hands 
and Raynaud's phenomenon, increased CPK, constitutional disease activity, severity of dysphagia, and poor prognosis [61]. Anti-Ku was originally found in a variety of connective tissue disease conditions, being associated with higher rates of arthralgia, Raynaud's phenomenon, musculoskeletal manifestations, and a high frequency of interstitial lung disease [60]. Finally, patients with antiU1-RNP rarely have myositis at initial presentation and respond favorably to glucocorticoid treatment, suggesting that this is a marker of good prognosis [59].

Myositis-specific autoantibodies are not essential to the treatment but are useful in some cases, especially when it is not possible to obtain a definitive diagnosis with muscle biopsy, being useful to accrue prognostic information and evaluate associated manifestations (B) $[60,61]$.

\section{Recommendations}

Autoantibodies can be found in patients diagnosed with SAM. They are not essential to the treatment but are useful in doubtful cases to accrue prognostic information and associated manifestations (quality of evidence B; level of agreement $>90 \%$ ).

\section{In the initial and late phases, which types of cancers should be searched for SAM? How often should the screening be done?}

From 36,547 records identified through database searching, 18 studies were selected to answer the present question (Additional file 1).

\section{Literature review and analysis}

Individuals with DM present a higher risk of malignancy compared to those diagnosed with PM (overall relative risk of 4.6 and 1.7, respectively) (A) [62], Although increased incidence of cancer in these patients can partially be attributed to the investigations requested for these individuals, particularly during the first year after diagnosis in tertiary centers (B) [63], evidence has pointed to a real higher incidence even before the diagnosis is established, thus suggesting a true association between the diagnosis of SAM and cancer (A) [64]. Despite the recognition of this association, the types of cancer remain somewhat controversial, including a broad spectrum of malignancies such as breast, lung colorectal, nasopharynx, body of the uterus, and gastric cancer, which are significantly influenced by gender and ethnicity [62-69].

In particular, a multicenter study of patients with DM found a significantly elevated risk for lung, ovarian, pancreatic, gastric, and colorectal cancer and non-Hodgkin's lymphoma [69]. In patients with PM, an increased risk of non-Hodgkin's lymphoma and lung and bladder cancer was observed (B) [70]. The most common type of cancer was adenocarcinoma, accounting for $70 \%$ of all tumors associated with both diseases (B) [70].

There is a higher risk of neoplasms occurring among older individuals (B) [71, 72]. The evaluation should include prostate and testicular examination in men, breast and pelvic examination in women and rectal examination in all patients. Women with a recent SAM diagnosis should be extensively examined and submitted to mammography and pelvic ultrasonography [71, 72]. Some neoplasms may not yet be identified in a screening program such as lymphoma, ovarian, pancreatic, or lung cancer [71, 72]. Thus, computed tomography examination of the thorax, abdomen, and pelvis may be considered in a subgroup of patients with SAM who have risk factors for specific types of neoplasia, such as a positive family history of ovarian or breast cancer [71, 72]. Gastrointestinal endoscopy and colonoscopy should be utilized on a case-by-case basis [71, 72].

Studies show a lack of uniformity in the definition of the temporal association between neoplasia and the diagnosis of SAM [62-72]. Thus, there has been no consensus until recently regarding how and when this screening should be conducted.

\section{Recommendations}

There is no concise information about the screening of neoplasms, and no consensus, regarding how and when this screening should be conducted. However, in our opinion, adults with this diagnosis, highlighting DM, should be screened, requesting specific tests mainly according to gender, age, ethnicity, and familiar history (quality of evidence B; level of agreement $>90 \%$ ).

\section{Which comorbidities should be (re) evaluated regularly in patients with SAM?}

From 36,547 records identified through database searching, 22 studies were selected to answer the present question (Additional file 1).

\section{Literature review and analysis}

Virtually all individuals with conditions associated with muscle weakness, such as those found in SAM, are susceptible to the development of low bone mass density (B) $[73-75]$ (A) $[76,77]$. Moreover, these individuals are exposed to an additional risk factor since glucocorticoids represent the first-line treatment (B) [78] (D) [79, 80]. Individuals who face significant deterioration of bone mass density and/or bone microarchitecture impairment are at a high risk of fracture (A) [81], making it imperative to periodically investigate using the $\mathrm{X}$-ray dualdensity densitometry method (B) [82]. An observational study conducted with the objective of assessing the prevalence of osteoporosis and occurrence of fractures in adults with SAM identified that osteoporosis was 
more frequently diagnosed compared to controls with a high prevalence of fractures (B) [82].

Although rarely symptomatic, subclinical cardiac manifestations are usually identified in patients with myopathies, and their prevalence varies widely according to the way the patient is investigated (electrocardiogram, echocardiogram, Holter, cardiac MRI) [83, 84]. The most frequent abnormalities are cardiomyopathy, dilated cardiomyopathy, heart failure, myocarditis, pericarditis, conduction defects and arrhythmias (A) [83] (D) [84]. The occurrence of arterial microvascular disease associated with acute myocardial infarction has also been reported [84, 85]. Nevertheless, patients may demonstrate combinations of more than one type of heart involvement $[84,85]$. Clinical evaluation, including detailed anamnesis and physical examination is of paramount importance at the time of diagnosis, and some tests are recommended, such as an electrocardiogram, to check for cardiac involvement with the presence of arrhythmias and conduction abnormalities (C) [85]. Other investigations such as echocardiography, myocardial scintigraphy, and MRI are indicated when clinically relevant at the time of diagnosis and during the follow-up period (C) [86].

The lung is the organ most frequently affected in SAM, which is also the main cause of death in this group of patients [84]. The main types of lung involvement are hypoventilation due to respiratory muscle weakness, interstitial pneumonia, and aspiration (D) [87] (B) [88]. Therefore, patients with myopathies should undergo pulmonary function evaluation at the time of diagnosis. Moreover, patients with a high risk of pulmonary function impairment and/or vital capacity reduction should be monitored more frequently (B) [88-90]. In these cases, assessment of noninvasive oxygenation of patients by oximetry may be indicated. The evaluation of pulmonary function may also include a 6min walking test, respiratory video fluoroscopy and ergospirometry [88-90].

Dysphagia has been reported in $32-84 \%$ of SAM patients, and esophageal involvement assessed by highresolution manometry is common in patients with SAM, but it correlates poorly with esophageal symptoms. Failed waves and decreased upper esophageal sphincter pressure are more common in PM than in DM patients (B) [91].

\section{Recommendations}

The management of patients with myopathies should consider care aimed at limiting the effects of muscle weakness, on joints, bones and other systems. In addition, comorbidities should be screened for and treated when necessary, optimizing the functional capacity and thereby improving quality of life of patients (quality of evidence B; level of agreement $>90 \%$ ).

\section{What are the main differential diagnoses of SAM?}

From 36,547 records identified through database searching, 9 studies were selected to answer the present question (Additional file 1).

\section{Literature review and analysis}

The identification of certain extramuscular manifestations may suggest the possibility of mitochondrial myopathy such as the presence of cognitive alterations, hearing and extraocular muscle impairment, convulsions, and neuropathy in patients with mitochondrial encephalomyopathy (D) [92]. Serum CK levels may be normal, and muscle biopsy stained by the Gomori trichrome revealed the presence of fibers with increased reddish granulation [92]. It should be noted, however, that although these findings are indicative of mitochondrial dysfunction, they may be identified in many other disorders and are not specific to the diagnosis of hereditary mitochondrial myopathy (D) [93].

Another important differential diagnosis is metabolic myopathies, characterized by defects in muscle tissue utilization of carbohydrates or fats, resulting in a decrease in energy supply [94, 95]. These myopathies manifest as cramp attacks and muscle weakness, often associated with myoglobinuria [94, 95]. Some metabolic myopathies, such as acid maltase deficiency (Pompe's disease) and glycogen storage disease type V (McArdle's disease) may manifest with episodic proximal muscle weakness $[75,94]$. This pattern may eventually lead to confusion with the diagnosis of SAM, especially in the presence of a history of chronicity and nonidentification of myoglobinuria (C) $[94,95]$.

Endocrine myopathies should also be considered in the differential diagnosis [96]. Myopathy related to hypothyroidism is typically characterized by muscle discomfort associated with mild to moderate proximal muscle weakness [96]. Serum CK levels may be slightly elevated, and there appears to be no association between the degree of muscle weakness and the severity of hypothyroidism (B) [96]. Hyperthyroidism is also associated with myopathy, although it seems to be a less common occurrence than that observed in cases of hypothyroidism [96]. A study identified that approximately $60 \%$ of patients with untreated hyperthyroidism showed clinical evidence of proximal muscle weakness; however, only $10 \%$ had myopathic changes in electromyography (B) [95]. Hyperparathyroidism may occasionally cause proximal muscle weakness syndrome. Additionally, CK levels that are normal or slightly elevated with muscle biopsy may indicate atrophy without alteration in muscle fiber arrangement [96].

Drug-induced myopathies are also a differential diagnosis [97]. As a classic example, statins may be associated with varying forms of muscle symptoms and toxicity, such as myalgia (1 to $10 \%$ ), myositis (defined by muscle symptoms and increased CK levels), and rhabdomyolysis (increases in 
CK with evidence of injury) (D), most commonly observed in patients with hypothyroidism, in those who are using multiple drugs, and even in those who abuse alcoholic beverages (D) [97].

Some infections may cause chronic myopathy that may resemble PM [98]. These infections are often triggered by acute viral illness, such as the Coxsackie or influenza virus [98]. Human immunodeficiency virus may also be associated with muscle weakness, either as a characteristic of the infection itself or in later stages of the disease [98]. In addition to myopathic changes, there may be evidence of axonal sensory neuropathy [98]. Bacterial infections, except for Lyme disease and syphilis, may present with focal pyomyositis (D) [98].

Finally, muscular dystrophies should also be considered as differential diagnoses, mainly in PM or PM-like conditions, since these conditions may mimic the clinical manifestations of SAM. Some features may suggest the diagnosis of muscular dystrophies, such sa positive family history, prolonged course of muscle weakness, facial weakness, abnormalities of eye movement, distal weakness equal to or greater than proximal weakness, and asymmetrical weakness.

\section{Recommendations}

Several conditions may mimic the clinical manifestations of SAM. Moreover, the absence of specific autoantibodies and systemic features related to autoimmunity and refractoriness to immunosuppressive drugs should also raise the suspicion of alternative diagnoses (quality of evidence B; level of agreement > 90\%).

\section{Which clinical / laboratory findings result in poor response to drug treatment in SAM?}

From 9275 records identified through database searching, 14 studies were selected to answer the present question (Additional file 1).

\section{Literature review and analysis}

The International Myositis Assessment \& Clinical Studies Group (IMACS) suggested, regarding the status of the disease, some measures as a global evaluation of the disease activity perceived by the patient and physician. Muscle strength assessed by Muscle Manual Testing (MMT); functional capacity measured by the Health Assessment Questionnaire (HAQ); elevated serum levels of at least two muscle enzymes ( $\mathrm{CK}$, aldolase, lactate dehydrogenase, aspartate and alanine aminotransferases); and extramuscular manifestations of the disease assessed by the Myositis Disease Activity Assessment Tool (MDAAT) may be used for the purpose of monitoring disease activity and as indicative of poor response to treatment (D) [99]. However, in addition to few measures being fully validated, it is still difficult to differentiate disease activity from accrual damage [99].
Despite the relationship with ILD, antisynthetase antibody positivity is a predictor of clinical response to rituximab in individuals with refractory myositis (B) [100-102]. Reports indicate that patients with ILD-positive anti-OJ present a good prognosis as well as a positive response to glucocorticoid therapy (C) [103]. Anti-exosome (anti-PM/Scl) presence does not appear to be a good prognostic factor and is associated with pulmonary and esophageal involvement (C) [104].

\section{Recommendations}

Cytokines and specific or related myositis antibodies aiming to discriminate the disease activity and to predict the prognosis of the treatment. However, it is important to note that the available evidence on the use of laboratory findings for this purpose shows variable results in terms of performance, lacking a standardized approach (quality of evidence B; level of agreement $>90 \%$ ).

The available evidence on the use of laboratory tests or other standardized tools to evaluate disease activity and/or to predict the response to treatment shows variable results in terms of performance, lacking a standardized approach. At this point, we recommend the use of laboratory markers, such as CPK, and tools, such as physician and patient global evaluation of the disease activity as guides to disease activity, and treatment response (quality of evidence B; level of agreement > 90\%).

\section{Which organs and/or systems should be routinely reevaluated in patients with SAM?}

From 36,892 records identified through database searching, 20 studies were selected to answer the present question (Additional file 1).

\section{Literature review and analysis}

In addition to the considerable heterogeneity in the presentation and prognosis of the SAM, extramuscular involvement is often observed. There may be concurrent involvement of cardiovascular, respiratory, digestive, kidney, endocrine, ocular, dermatological, hematological, and nervous systems (B) [83, 87, 105-109]. The extent and severity of systemic organ involvement also vary substantially in each SAM category (DM, PM, immunemediated necrotizing myopathy) [83, 87, 105-109].

SAM patients present survival rates estimated between approximately 60 and $70 \%$, with deaths mainly related to cardiac and pulmonary involvement, as well as the occurrence of cancers and infections affecting the respiratory and gastrointestinal tract (B) $[88,110]$. The cause of death in individuals depends on the duration of the disease. Death related to pulmonary complications usually occurs in the first year of disease, while cardiovascular complications are the most common cause of death 5 years after diagnosis (B) [111]. Therefore, all individuals should be referred for cardiac and lung function assessment at the time of diagnosis 
of SAM, and clinical evaluation, including detailed anamnesis and physical examination is essential [108]. Some tests are recommended, such as electrocardiogram and the evaluation of pulmonary function, to verify cardiac involvement with arrhythmias and conduction abnormalities and impairment of pulmonary function as a reduction in vital capacity (B) $[90,112](C)[85](D)[113]$.

Gastrointestinal disorders compromise the oropharynx, esophagus, stomach, liver, small intestine, colon, and rectum, and there is a substantial increase in the risk of occult malignancies, including gastrointestinal cancers, mainly observed in the first year after diagnosis (B) [70, 114, 115]. Thus, extensive anamnesis and physical examination are mandatory in newly diagnosed patients, and a high suspicion of underlying malignancy should be maintained. High-risk characteristics for malignancy include advanced age, myopathy refractory to glucocorticoid treatment, presence of severe cutaneous rash, and being negative for some autoantibodies [anti-histidyl tRNA synthetase (Jo-1), anti$\mathrm{PM} / \mathrm{Scl}$, anti-U1-RNP, anti-U3-RNP and anti-Ku antigen] $[116,117]$, requiring a more complete evaluation in regard to cancer screening and surveillance.

\section{Recommendations}

The manifestation of SAM is heterogeneous. Therefore, cardiovascular, respiratory and gastrointestinal evaluations should be performed when indicated. Care should also be taken to ensure a neoplasm screening and surveillance program (quality of evidence B; level of agreement > 90\%).

\section{Conclusions}

Among all criteria, the EULAR / ACR 2017 stands out for the diagnosis of SAM. Muscular biopsy is essential, aided by muscular magnetic resonance images and electroneuromyography in complementary research. Analysis of factors related to prognosis with evaluation of extramuscular manifestations, and comorbidities and intense investigation regarding differential diagnoses are mandatory.

\section{Supplementary information}

Supplementary information accompanies this paper at https://doi.org/10. 1186/s42358-019-0085-5.

Additional file 1. The studies selection process during the systematic review. (DOCX $23 \mathrm{~kb}$ )

\footnotetext{
Abbreviations

ACR: American College of Rheumatology; CDASI: Cutaneous dermatomyositis disease area; CPK: Creatine phosphokinase; DM: Dermatomyositis; ENMC: European Neuromuscular Center; EULAR: European League Against Rheumatism; HAQ: Health Assessment Questionnaire; HMGCR: 3-hydroxy-3methylglutaryl-coenzyme A reductase; IL: Interleukin; ILD: Interstitial lung disease; IMACS: International Myositis Assessment and Clinical Studies Group; IP: Interferon gamma-induced protein; MDA: Melanoma differentiationassociated gene; MDAAT: Myositis Disease Activity Assessment Tool; MMT: Muscle Testing Manual; MRI: Magnetic resonance imaging;
}

NXP: Nuclear Matrix Protein; PICO: Patient, Intervention, Control, Outcome; PM: Polymyositis; RCT: Randomized controlled trials; RNP: Nuclear ribonucleoprotein; SAM: Systemic autoimmune myopathies; SDF: Stromal cell-derived factor; SRP: Signal recognition particle; TIF: Transcriptional intermediary factor; TNF: Tumor necrosis factor

\section{Acknowledgments}

Renata Miossi, and Mailze Campos Bezerra who contributed to the elaboration of questions.

\section{Authors' contributions}

FHCS contributed to the elaboration of questions. He was a major contributor in writing and reviewing the manuscript. DBA contributed to the elaboration of questions and the manuscript revision. VSS contributed to the elaboration of question and the manuscript revision. RSS contributed to systematic literature review. WMB contributed to systematic literature review. TAF contributed to systematic literature review. BMC contributed to the elaboration of questions and the manuscript revision. SKS contributed to the manuscript organization, elaboration of questions and manuscript revision. All authors read and approved the final manuscript.

\section{Funding}

Brazilian Society of Rheumatology.

Availability of data and materials

Not applicable

Ethics approval and consent to participate

Not applicable

Consent for publication

Not applicable

\section{Competing interests}

All authors declare that they have no competing interests.

\section{Author details}

${ }^{1}$ Hospital das Clinicas HCFMUSP, Faculdade de Medicina, Universidade de Sao Paulo, São Paulo, SP, Brazil. ${ }^{2}$ Universidade Federal de Pelotas (UFP), Pelotas, RS, Brazil. ${ }^{3}$ Universidade do Estado do Rio de Janeiro (UERJ), Rio de Janeiro, RJ, Brazil. ${ }^{4}$ Programa Diretrizes da Associação Médica Brasileira (AMB), Brasília, Brazil. ${ }^{5}$ Rede Sarah de Hospitais de Reabilitação, Brasília, Brazil. ${ }^{6}$ Disciplina de Reumatologia, Faculdade de Medicina FMUSP, Universidade de Sao Paulo, Av. Dr. Arnaldo, 455, $3^{\circ}$ andar, sala 3150, Sao Paulo, Cerqueira César CEP: 01246-903, Brazil.

Received: 15 November 2018 Accepted: 10 September 2019

Published online: 10 October 2019

\section{References}

1. Feldman BM, Rider LG, Reed AM, Pachman LM. Juvenile dermatomyositis and other idiopathic inflammatory myopathies of childhood. Lancet. 2008;371:201-12.

2. Lundberg IE, Tjamlund A, Bottai M, Pikington C, de Visser M, Alfredson L, et al. 2017 European league against rheumatism / American College of Rheumatology classification criteria for adult and juvenile idiopathic inflammatory myopathies and their major subgroups. Arthritis Rheum. 2017;69:2271-82.

3. Dalakas MC. Inflammatory muscle diseases. N Engl J Med. 2015:372:1734-47.

4. Lundberg IE, Miller FW, Tjärnlund A, Bottai M. Diagnosis and classification of idiopathic inflammatory myopathies. J Intern Med. 2016;280:39-51.

5. Iberati A, Altman DG, Tetzlaff J, Mulrow C, Gøtzsche PC, loannidis JP, et al. The PRISMA statement for reporting systematic reviews and meta-analyses of studies that evaluate healthcare interventions: explanation and elaboration. BMJ. 2009;339:b2700

6. Guyatt GH, Oxman AD, Vist GE, Kunz R, Falck-Ytter Y, Alonso-Coello P, et al. GRADE: an emerging consensus on rating quality of evidence and strength of recommendations. BMJ. 2008;336:924-6.

7. Guyatt GH, Oxman AD, Kunz R, Falck-Ytter Y, Vist GE, Liberati A, et al. GRADE working group. Going from evidence to recommendations. BMJ. 2008;336:1049-51. 
8. Guyatt GH, Oxman AD, Vist GE, Kunz R, Falck-Ytter Y, Alonso-Coello P, et al. GRADE working group. GRADE: an emerging consensus on rating quality of evidence and strength of recommendations. BMJ. 2008;336:924-6.

9. Linklater $\mathrm{H}$, Pipitone N, Rose MR, Norwood F, Campbell R, Salvarani C, et al. Classifying idiopathic inflammatory myopathies: comparing the performance of six existing criteria. Clin Exp Rheumatol. 2013;31:767-9.

10. Bohan A, Peter JB. Polymyositis and dermatomyositis (first of two parts). N Engl J Med. 1975;292:344-7.

11. Bohan A, Peter JB. Polymyositis and dermatomyositis (second of two parts). N Engl J Med. 1975;292:403-7.

12. Hoogendijk JE, Amato AA, Lecky BR, Choy EH, Lundberg IE, Rose MR, et al. 119th ENMC international workshop: trial design in adult idiopathic inflammatory myopathies, with the exception of inclusion body myositis, 10-12 October 2003, Naarden, the Netherlands. Neuromuscul Disord. 2004;14:337-45.

13. Tanimoto K, Nakano K, Kano S, Mori S, Ueki H, Nishitani H, et al. Classification criteria for polymyositis and dermato-myositis. J Rheumatol. 1995;22:668-74.

14. Targoff IN, Miller FW, Medsger TA Jr, Oddis CV. Classification criteria for the idiopathic inflammatory myopathies. Curr Opin Rheumatol. 1997;9:527-35.

15. Patel B, Khan N, Werth VP. Applicability of EULAR/ACR classification criteria for dermatomyositis to amyopathic disease. J Am Acad Dermatol. 2018;79:77-83.

16. Hocevar A, Rotar Z, Krosel M, Cucnik S, Tomsic M. Performance of the 2017 European league against rheumatism/American College of Rheumatology classification criteria for adult and juvenile idiopathic inflammatory myopathies in clinical practice. Ann Rheum Dis. 2018;77:e90.

17. Dalakas MC, Hohlfeld R. Polymyositis and dermatomyositis. Lancet. 2003;362:971-82.

18. Nagappa M, Nalini A, Narayanappa G. Major histocompatibility complex and inflammatory cell subtype expression in inflammatory myopathies and muscular dystrophies. Neurol India. 2013;61:614-21.

19. Salaroli R, Baldin E, Papa V, Rinaldi R, Tarantino L, De Giorgi LB, et al. Validity of internal expression of the major histocompatibility complex class I in the diagnosis of inflammatory myopathies. J Clin Pathol. 2012;65:14-9.

20. Rodríguez Cruz PM, Luo YB, Miller J, Junckerstorff RC, Mastaglia FL, Fabian V. An analysis of the sensitivity and specificity of MHC-I and MHC-II immunohistochemical staining in muscle biopsies for the diagnosis of inflammatory myopathies. Neuromuscul Disord. 2014;24:1025-35.

21. Jain A, Sharma MC, Sarkar C, Bhatia R, Singh S, Handa R. Major histocompatibility complex class I and II detection as a diagnostic tool in idiopathic inflammatory myopathies. Arch Pathol Lab Med. 2007;131:1070-6.

22. van der Pas J, Hengstman GJ, ter Laak HJ, Borm GF, van Engelen BG. Diagnostic value of MHC class I staining in idiopathic inflammatory myopathies. J Neurol Neurosurg Psychiatry. 2004;75:136-9.

23. Sallum AM, Kiss MH, Silva CA, Wakamatsu A, Sachetti $S$, Lotufo $S$, et al. MHC class I and II expression in juvenile dermatomyositis skeletal muscle. Clin Exp Rheumatol. 2009;27:519-26.

24. Dai TJ, Li W, Zhao QW, Zhao YY, Liu SP, Yan CZ. CD8/MHC-I complex is specific but not sensitive for the diagnosis of polymyositis. J Int Med Res. 2010;38:1049-59.

25. O'Connell MJ, Powell T, Brennan D, Lynch T, McCarthy CJ, Eustace SJ. Whole-body MR imaging in the diagnosis of polymyositis. AJR Am J Roentgenol. 2002;179:967-71

26. Elessawy SS, Abdelsalam EM, Abdel Razek E, Tharwat S. Whole-body MRI for full assessment and characterization of diffuse inflammatory myopathy. Acta Radiol Open. 2016;5:2058460116668216.

27. Van De Vlekkert J, Maas M, Hoogendijk JE, De Visser M, Van Schaik IN. Combining MRI and muscle biopsy improves diagnostic accuracy in subacute-onset idiopathic inflammatory myopathy. Muscle Nerve. 2015;51:253-8.

28. Lyu RK, Cornblath DR, Chaudhry V. Incidence of irritable electromyography in inflammatory myopathy. J Clin Neuromuscul Dis. 1999;1:64-7.

29. Blijham PJ, Hengstman GJ, Ter Laak HJ, Van Engelen BG, Zwarts MJ. Musclefiber conduction velocity and electromyography as diagnostic tools in patients with suspected inflammatory myopathy: a prospective study. Muscle Nerve. 2004;29:46-50.

30. Yang $F$, Jing F, Chen $Z$, Ling L, Wang $R$, Wang $X$, et al. Electrophysiological and clinical examination of polymyositis: a retrospective analysis. Am J Med Sci. 2014;348:162-6.

31. Pugdahl K, Johnsen B, Tankisi H, Camdessanch JP, de Carvalho M, Fawcett PR, et al. Added value of electromyography in the diagnosis of myopathy: a consensus exercise. Clin Neurophysiol. 2017;128:697-701.

32. Kim NR, Nam EJ, Kang JW, Song HS, Im CH, Kang YM. Complex repetitive discharge on electromyography as a risk factor for malignancy in idiopathic inflammatory myopathy. Korean J Intern Med. 2014;29:814-21.
33. Mechler F. Changing electromyographic findings during the chronic course of polymyositis. J Neurol Sci. 1974;23:237-42.

34. Sandstedt PE, Henriksson KG, Larrsson LE. Quantitative electromyography in polymyositis and dermatomyositis. Acta Neurol Scand. 1982;65:110-21.

35. Jian F, Cui LY, Li BH, Du H. Changes of single fiber electromyography in patients with inflammatory myopathies. Chin Med Sci J. 2005;20:1-4.

36. Blijham PJ, Hengstman GJ, Hama-Amin AD, van Engelen BG, Zwarts MJ. Needle electromyographic findings in 98 patients with myositis. Eur Neurol. 2006:55:183-8.

37. Lega JC, Fabien N, Reynaud Q, Durieu I, Durupt S, Dutertre M, et al. The clinical phenotype associated with myositis-specific and associated autoantibodies: a meta-analysis revisiting the so-called antisynthetase syndrome. Autoimmun Rev. 2014;13:883-91.

38. Hengstman GJ, Brouwer R, Egberts WT, Seelig HP, Jongen PJ, van Venrooij WJ, et al. Clinical and serological characteristics of 125 Dutch myositis patients. Myositis specific autoantibodies aid in the differential diagnosis of the idiopathic inflammatory myopathies. J Neurol. 2002;249:69-75.

39. Zampeli E, Venetsanopoulou A, Argyropoulou OD, Mavragani CP, Tektonidou MG, Vlachoyiannopoulos PG, et al. Myositis autoantibody profiles and their clinical associations in Greek patients with inflammatory myopathies. Clin Rheumatol. 2018;38(1):125.

40. Nishikai M, Reichlin M. Heterogeneity of precipitating antibodies in polymyositis and dermatomyositis. Characterization of the Jo-1 antibody system. Arthritis Rheum. 1980;23:881-8.

41. Hamaguchi Y, Fujimoto M, Matsushita T, Kaji K, Komura K, Hasegawa M, et al. Common and distinct clinical features in adult patients with antiaminoacyl-tRNA synthetase antibodies: heterogeneity within the syndrome. PLoS One. 2013;8:e60442.

42. Klein M, Mann H, Pleštilová L, Betteridge Z, McHugh N, Remáková M, et al. Arthritis in idiopathic inflammatory myopathy: clinical features and autoantibody associations. J Rheumatol. 2014;41:1133-9.

43. Koga T, Fujikawa K, Horai Y, Okada A, Kawashiri SY, Iwamoto N, et al. The diagnostic utility of anti-melanoma differentiation-associated gene 5 antibody testing for predicting the prognosis of Japanese patients with DM. Rheumatology (Oxford). 2012;51:1278-84.

44. Chen Z, Cao M, Plana MN, Liang J, Cai H, Kuwana M, et al. Utility of antimelanoma differentiation-associated gene 5 antibody measurement in identifying patients with dermatomyositis and a high risk for developing rapidly progressive interstitial lung disease: a review of the literature and a meta-analysis. Arthritis Care Res. 2013;65:1316-24.

45. Gono T, Sato S, Kawaguchi Y, Kuwana M, Hanaoka M, Katsumata Y, et al. Anti-MDA5 antibody, ferritin and IL-18 are useful for the evaluation of response to treatment in interstitial lung disease with anti-MDA5 antibodypositive dermatomyositis. Rheumatology (Oxford). 2012;51:1563-70.

46. Endo $Y$, Koga T, Suzuki T, Hara K, Ishida M, Fujita Y, et al. Successful treatment of plasma exchange for rapidly progressive interstitial lung disease with anti-MDA5 antibody-positive dermatomyositis: a case report. Medicine (Baltimore). 2018;97:e0436.

47. Moghadam-Kia S, Oddis CV, Sato S, Kuwana M, Aggarwal R. Anti-melanoma differentiation-associated gene 5 is associated with rapidly progressive lung disease and poor survival in us patients with amyopathic and myopathic dermatomyositis. Arthritis Care Res. 2016:68:689-94.

48. Aggarwal R, Cassidy E, Fertig N, Koontz DC, Lucas M, Ascherman DP, et al. Patients with non-Jo-1 anti-tRNA-synthetase autoantibodies have worse survival than Jo-1 positive patients. Ann Rheum Dis. 2014;73:227-32.

49. Suzuki S, Hayashi YK, Kuwana M, Tsuburaya R, Suzuki N, Nishino I. Myopathy associated with antibodies to signal recognition particle: disease progression and neurological outcome. Arch Neurol. 2012;69:728-32.

50. Wang L, Liu L, Hao H, Gao F, Liu X, Wang Z, et al. Myopathy with anti-signal recognition particle antibodies: clinical and histopathological features in Chinese patients. Neuromuscul Disord. 2014;24:335-41.

51. Kao AH, Lacomis D, Lucas M, Fertig N, Oddis CV. Anti-signal recognition particle autoantibody in patients with and patients without idiopathic inflammatory myopathy. Arthritis Rheum. 2004;50:209-15.

52. Allenbach $Y$, Drouot $L$, Rigolet $A$, Charuel $J$, Jouen F, Romero NB, et al. French myositis network. Anti-HMGCR autoantibodies in European patients with autoimmune necrotizing myopathies: inconstant exposure to statin. Medicine (Baltimore). 2014;93:150-7.

53. Mohassel P, Mammen AL. Anti-HMGCR myopathy. J Neuromuscul Dis. 2018:5:11-20

54. Tiniakou E, Pinal-Fernandez I, Lloyd TE, Albayda J, Paik J, Werner JL, Parks $C A$, et al. More severe disease and slower recovery in younger patients with 
anti-3-hydroxy-3-methylglutaryl-coenzyme a reductase-associated autoimmune myopathy. Rheumatology (Oxford). 2017;56:787-94.

55. Targoff IN, Reichlin M. The association between anti-Mi2 antibodies and dermatomyositis. Arthritis Rheum. 1985;28:796-803.

56. Kaji K, Fujimoto M, Hasegawa M, Kondo M, Saito Y, Komura K, et al. Identification of a novel autoantibody reactive with p155 and $140 \mathrm{kDa}$ nuclear proteins in patients with dermatomyositis: an association with malignancy. Rheumatology (Oxford). 2007;46:25-8.

57. Targoff IN, Mamyrova G, Trieu EP, Perurena O, Koneru B, O'Hanlon TP, et al A novel autoantibody to a 155-kd protein is associated with dermatomyositis. Arthritis Rheum. 2006;54:3682-9.

58. Albayda J, Pinal-Fernandez I, Huang Y, Parks C, Casciola-Rosen L, Danoff SK, et al. Antinuclear matrix protein 2 autoantibodies and edema, muscle disease and malignancy risk in dermatomyositis patients. Arthritis Care Res. 2017:69:1771-6.

59. Fredi $M$, Cavazzana I, Franceschini F. The clinic-serological spectrum of overlap myositis. Curr Opin Rheumatol. 2018;30:637-43.

60. Rigolet A, Musset L, Dubourg O, Maisonobe T, Grenier P, Charuel JL, et al. Inflammatory myopathies with anti-Ku antibodies: a prognosis dependent on associated lung disease. Medicine (Baltimore). 2012;91:95-102.

61. Muro Y, Hosono Y, Sugiura K, Ogawa Y, Mimori T, Akiyama M. Anti-PM/Scl antibodies are found in Japanese patients with various systemic autoimmune conditions besides myositis and scleroderma. Arthritis Res Ther. 2015;17:57.

62. Qiang JK, Kim WB, Baibergenova A, Alhusayen R. Risk of malignancy in dermatomyositis and polymyositis. J Cutan Med Surg. 2017;21:131-6.

63. Zhang $Y$, Felson D. The overall and temporal association of cancer with polymyositis and dermatomyositis. J Rheumatol. 1994;21:1855-9.

64. Yang Z, Lin F, Qin B, Liang Y, Zhong R. Polymyositis/dermatomyositis and malignancy risk: a meta-analysis study. J Rheumatol. 2015;42:282-91.

65. Chen YJ, Wu CY, Huang YL, Wang CB, Shen JL, Chang YT. Cancer risks of dermatomyositis and polymyositis: a nationwide cohort study in Taiwan. Arthritis Res Ther. 2010;12:R70.

66. Azuma K, Yamada H, Ohkubo M, Yamasaki Y, Yamasaki M, Mizushima M, al e. Incidence and predictive factors for malignancies in 136 Japanese patients with dermatomyositis, polymyositis and clinically amyopathic dermatomyositis. Mod Rheumatol. 2011;21:178-83.

67. Wakata N, Kurihara T, Saito E, Kinoshita M. Polymyositis and dermatomyositis associated with malignancy: a 30-year retrospective study. Int J Dermatol. 2002;41:729-34.

68. Toumi S, Ghnaya H, Braham A, Harrabi I, Laouani-Kechrid C. Groupe tunisien d'étude des myosites inflammatoires. [polymyositis and dermatomyositis in adults. Tunisian multicentre study]. Rev Med Interne. 2009;30:747-53.

69. Diallo M, Fall AK, Diallo I, Diédhiou I, Ba PS, Diagne M, et al. Dermatomyositis and polymyositis: 21 cases in Senegal. Med Trop (Mars). 2010;70:166-8.

70. Hill CL, Zhang Y, Sigurgeirsson B, Pukkala E, Mellemkjaer L, Airio A, et al. Frequency of specific cancer types in dermatomyositis and polymyositis: a population-based study. Lancet. 2001;357:96-100.

71. Chow WH, Gridley G, Mellemkjaer L, McLaughlin JK, Olsen JH, Fraumeni JF Jr. Cancer risk following polymyositis and dermatomyositis: a nationwide cohort study in Denmark. Cancer Causes Control. 1995;6:9-13.

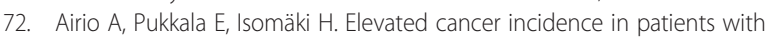
dermatomyositis: a population based study. J Rheumatol. 1995;22:1300-3.

73. Heinonen A, Kannus P, Sievänen H, Pasanen M, Oja P, Vuori I. Good maintenance of high-impact activity-induced bone gain by voluntary, unsupervised exercises: an 8-month follow-up of a randomized controlled trial. J Bone Miner Res. 1999;14:125-8.

74. Kalluru R, Hart H, Corkill M, Ng KP. Long-term follow-up of patients with idiopathic inflammatory myopathy at Waitemata District health board. N Z Med J. 2016;129:50-6.

75. So H, Yip ML, Wong AK. Prevalence and associated factors of reduced bone mineral density in patients with idiopathic inflammatory myopathies. Int J Rheum Dis. 2016;19:521-8.

76. Martyn-St James M, Carroll S. Effects of different impact exercise modalities on bone mineral density in premenopausal women: a meta-analysis. J Bone Miner Metab. 2010;28:251-67.

77. Marques EA, Mota J, Carvalho J. Exercise effects on bone mineral density in older adults: a meta-analysis of randomized controlled trials. Age (Dordr). 2012;34:1493-515.

78. van de Vlekkert J, Hoogendijk JE, de Haan RJ, Algra A, van der Tweel I, van der Pol WL. Et al; Dexa myositis trial. Oral dexamethasone pulse therapy versus daily prednisolone in sub-acute onset myositis, a randomized clinical trial. Neuromuscul Disord. 2010;20:382-9.
79. Compston J. Glucocorticoid-induced osteoporosis: an update. Endocrine. 2018;61:7-16.

80. Sato AY, Peacock M, Bellido T. Glucocorticoid excess in bone and muscle. Clin Rev Bone Miner Metab. 2018;16:33-47.

81. Health Quality Ontario. Utilization of DXA bone mineral densitometry in Ontario: an evidence-based analysis. Ont Health Technol Assess Ser. 2006;6:1-180.

82. de Andrade DC, de Magalhães Souza SC, de Carvalho JF, Takayama L, Borges CT, Aldrighi JM, et al. High frequency of osteoporosis and fractures in women with dermatomyositis/polymyositis. Rheumatol Int. 2012;32:1549-53.

83. Zhang L, Wang GC, Ma L, Zu N. Cardiac involvement in adult polymyositis or dermatomyositis: a systematic review. Clin Cardiol. 2012;35:686-91.

84. Lundberg IE. The heart in dermatomyositis and polymyositis. Rheumatology (Oxford). 2006;45:iv18-21.

85. Stern R, Godbold JH, Chess Q, Kagen LJ. ECG abnormalities in polymyositis. Arch Intern Med. 1984;144:2185-9.

86. Allanore $Y$, Vignaux O, Arnaud L, Puéchal X, Pavy S, Duboc D, et al. Effects of corticosteroids and immunosuppressors on idiopathic inflammatory myopathy related myocarditis evaluated by magnetic resonance imaging. Ann Rheum Dis. 2006:65:249-52.

87. Fathi M, Lundberg IE, Tornling G. Pulmonary complications of polymyositis and dermatomyositis. Semin Respir Crit Care Med. 2007:28:451-8.

88. Obert J, Freynet O, Nunes H, Brillet PY, Miyara M, Dhote R, et al. Outcome and prognostic factors in a French cohort of patients with myositisassociated interstitial lung disease. Rheumatol Int. 2016;36:1727-35.

89. Fujisawa T, Hozumi H, Kono M, Enomoto N, Hashimoto D, Nakamura Y, et al. Prognostic factors for myositis-associated interstitial lung disease. PLoS One. 2014;9:e98824

90. Fujisawa $\mathrm{T}$, Hozumi H, Kono M, Enomoto N, Nakamura $\mathrm{Y}$, Inui $\mathrm{N}$, et al. Predictive factors for long-term outcome in polymyositis/dermatomyositisassociated interstitial lung diseases. Respir Investig. 2017:55:130-7.

91. Casal-Dominguez M, Pinal-Fernandez I, Mego M, Accarino A, Jubany L, Azpiroz F, et al. High-resolution manometry in patients with idiopathic inflammatory myopathy: elevated prevalence of esophageal involvement and differences according to autoantibody status and clinical subset. Muscle Nerve. 2017;56:386-92.

92. Magner M, Kolarova H, Honzik T, Svandová I, Zeman J. Clinical manifestation of mitochondrial diseases. Dev Period Med. 2015;19:441-9.

93. Milone M, Wong LJ. Diagnosis of mitochondrial myopathies. Mol Genet Metab. 2013;110:35-41.

94. Hagemans ML, Winkel LP, Van Doorn PA, Hop WJ, Loonen MC, Reuser AJ, et al. Clinical manifestation and natural course of late-onset Pompe's disease in 54 Dutch patients. Brain. 2005;128:671-7.

95. Lucia A, Ruiz JR, Santalla A, Nogales-Gadea G, Rubio JC, García-Consuegra I, et al. Genotypic and phenotypic features of McArdle disease: insights from the Spanish national registry. J Neurol Neurosurg Psychiatry. 2012;83:322-8.

96. Duyff RF, Van den Bosch J, Laman DM, van Loon BJ, Linssen WH. Neuromuscular findings in thyroid dysfunction: a prospective clinical and electrodiagnostic study. J Neurol Neurosurg Psychiatry. 2000;68:750-5.

97. Ramkumar S, Raghunath A, Raghunath S. Statin therapy: review of safety and potential side effects. Acta Cardiol Sin. 2016;32:631-9.

98. Crum-Cianflone NF. Bacterial, fungal, parasitic, and viral myositis. Clin Microbiol Rev. 2008;21:473-94.

99. Rider LG, Giannini EH, Harris-Love M, Joe G, Isenberg D, Pilkington C, et al. International myositis Assesment and clinical studies group. Defining clinical improvement in adult and juvenile myositis. J Rheumatol. 2003;30:603-17.

100. Aggarwal R, Bandos A, Reed AM, Ascherman DP, Barohn RJ, Feldman $\mathrm{BM}$, et al. Predictors of clinical improvement in rituximab-treated refractory adult and juvenile dermatomyositis and adult polymyositis. Arthritis Rheum. 2014:66:740-9.

101. Joffe MM, Love LA, Leff RL, Fraser DD, Targoff IN, Hicks JE, et al. Drug therapy of the idiopathic inflammatory myopathies: predictors of response to prednisone, azathioprine, and methotrexate and a comparison of their efficacy. Am J Med. 1993;94:379-87.

102. Koreeda Y, Higashimoto I, Yamamoto M, Takahashi M, Kaji K, Fujimoto $M$, et al. Clinical and pathological findings of interstitial lung disease patients with anti-aminoacyl-tRNA synthetase autoantibodies. Intern Med. 2010;49:361-9.

103. Kunimasa K, Arita M, Nakazawa T, Tanaka M, Tsubouchi K, Konishi S, et al. The clinical characteristics of two anti-OJ (anti-isoleucyl-tRNA synthetase) 
autoantibody-positive interstitial lung disease patients with polymyositis/ dermatomyositis. Intern Med. 2012;51:3405-10.

104. Marie I, Lahaxe L, Benveniste O, Delavigne K, Adoue D, Mouthon L, et al. Long-term outcome of patients with polymyositis / dermatomyositis and anti-PM-Scl antibody. Br J Dermatol. 2010;162:337-44.

105. Ng KP, Ramos F, Sultan SM, Isenberg DA. Concomitant diseases in a cohort of patients with idiopathic myositis during long-term follow-up. Clin Rheumatol. 2009;28:947-53.

106. Sultan SM, loannou Y, Moss K, Isenberg DA. Outcome in patients with idiopathic inflammatory myositis: morbidity and mortality. Rheumatology (Oxford). 2002:41:22-6.

107. Ríos $G$. Retrospective review of the clinical manifestations and outcomes in Puerto Ricans with idiopathic inflammatory myopathies. Clin Rheumatol. 2005;11:153-6.

108. Torres C, Belmonte R, Carmona L, Gómez-Reino FJ, Galindo M, Ramos B, et al. Survival, mortality and causes of death in inflammatory myopathies. Autoimmunity. 2006;39:205-15.

109. Diederichsen LP. Cardiovascular involvement in myositis. Curr Opin Rheumatol. 2017;29:598-603.

110. Nuño-Nuño L, Joven BE, Carreira PE, Maldonado-Romero V, Larena-Grijalba C, Cubas IL, et al. Mortality and prognostic factors in idiopathic inflammatory myositis: a retrospective analysis of a large multicenter cohort of Spain. Rheumatol Int. 2017;37:1853-61.

111. Amaral Silva M, Cogollo E, Isenberg DA. Why do patients with myositis die? A retrospective analysis of a single-Centre cohort. Clin Exp Rheumatol. 2016;34:820-6.

112. Deveza LM, Miossi R, de Souza FH, Shimabuco AY, Favarato MH, Grindler J, et al. Electrocardiographic changes in dermatomyositis and polymyositis. Rev Bras Reumatol. 2016;56:95-100.

113. Chen F, Peng Y, Chen M. Diagnostic approach to cardiac involvement in idiopathic inflammatory myopathies. Int Heart J. 2018;59:256-62.

114. Buchbinder R, Forbes A, Hall S, Dennett X, Giles G. Incidence of malignant disease in biopsy-proven inflammatory myopathy. A population-based cohort study. Ann Intern Med. 2001;134:1087-95.

115. András C, Ponyi A, Constantin T, Csiki Z, Szekanecz E, Szodoray P, et al. Dermatomyositis and polymyositis associated with malignancy: a 21-year retrospective study. J Rheumatol. 2008;35:438-44.

116. Ceribelli A, Isailovic N, De Santis M, Generali E, Fredi M, Cavazzana I, et al. Myositisspecific autoantibodies and their association with malignancy in Italian patients with polymyositis and dermatomyositis. Clin Rheumatol. 2017:36:469-75.

117. Chinoy H, Fertig N, Oddis CV, Ollier WE, Cooper RG. The diagnostic utility of myositis autoantibody testing for predicting the risk of cancer-associated myositis. Ann Rheum Dis. 2007;66:1345-9.

\section{Publisher's Note}

Springer Nature remains neutral with regard to jurisdictional claims in published maps and institutional affiliations.

Ready to submit your research? Choose BMC and benefit from:

- fast, convenient online submission

- thorough peer review by experienced researchers in your field

- rapid publication on acceptance

- support for research data, including large and complex data types

- gold Open Access which fosters wider collaboration and increased citations

- maximum visibility for your research: over $100 \mathrm{M}$ website views per year

At $\mathrm{BMC}$, research is always in progress.

Learn more biomedcentral.com/submissions 